\title{
Improving service responses for people with learning disabilities who have been sexually assaulted: an audit of forensic services
}

\section{Accessible Summary:}

- When people report being sexually assaulted they can be examined by a specially trained doctor to see how the assault might have affected them. They may also ask for help from a counsellor or other specially trained support workers. These staff might belong to a sexual assault referral centre (SARC).

- This paper reports findings from work that staff from St Mary's SARC in Manchester did so that they could improve the services they offer to people with learning disabilities who have been sexually assaulted.

- A staff survey showed that staff thought they might not always recognise if a person had learning disabilities or another learning difficulty like dyslexia. We wonder if knowing the difference is as important as knowing how to support people well. Looking at patient notes showed that patients with learning disabilities received less follow up care than patients without learning disabilities.

- This paper describes the first step that the St Mary's team took in order to improve their service. Improvements have been made since these first findings including some of those recommended by staff in their surveys. These will be reported in another paper to see if they have made a difference to people with learning disabilities.

Key words: learning disability; sexual assault; sexual abuse; medical examination; best interest decision; capacity to consent; neurodiversity

\footnotetext{
Abstract

Background: People with learning disabilities are more likely to experience sexual abuse and less likely to access support than the general population, this is due to a range of variables at the individual, societal and service-delivery level. This paper presents a service evaluation of St Mary's Sexual Assault Referral Centre, Manchester to explore its ability to provide meaningful support to people with learning disabilities and to identify ways to improve its responses.

Materials and Methods: The service evaluation had two components: (1) A staff survey to elicit self-perception of the knowledge and skills required to meaningfully support people with learning disabilities who attended the centre following an allegation of rape or sexual assault (2) An audit of patient notes to compare service delivered to patients with a learning disability to those without.
} 
Results: Forty-two members of staff (over $75 \%$ response rate) completed the survey which found a lack of differentiation between learning disabilities and other types of neurodiversity. The majority of responders reported having enough knowledge about learning disabilities to do their job and feeling confident in their abilities. Nonetheless, all the staff reported that they would like more learning disability training. An audit of the patients' notes found people with learning disabilities accessed fewer follow-up care services than people without learning disabilities.

Conclusions: The results identify areas for staff training to improve meaningful support for people with learning disabilities alongside a note of caution against a focus on labelling. By introducing more accessible support a diverse group of people can benefit.

\section{Introduction}

The issue of sexual abuse amongst people with learning disabilities was first brought to public attention in 1989 by Brown and Craft. At that time, many readers treated the notion of people with learning disabilities being victims of sexual abuse with resistance and denial (Brown, Stein \&Turk 1995). In subsequent years, studies continued to suggest that people with learning disabilities were more likely to be sexually assaulted than the general population (Brown and Turk 1994, Beail \& Warden 1995, Hogg, Campbell, Cullen \& Watson 2001). Subsequent research has sought to understand why and how people with learning disabilities appear to be over represented in terms of sexual assault when compared to the general population. For example Buchanan \& Wilkins (1991) suggested that approximately $8 \%$ of people with learning disability were likely to be sexually abused, whereas Hard and Plumb (cited in Peckham 2007) suggest the figure is closer to $83 \%$.

The difficulty in establishing prevalence may in some instances be due to authors conflating definitions for learning disabilities, learning difficulties and sensory disabilities when reporting findings (Brownridge 2006, Grossman and Lundy 2008, Powers, Hughes \& Lund 2011). It might also be a result of lack of clarity in defining rape, sexual assault and sexual abuse. Despite the discrepancy in figures, a growing body of evidence indicates that people with learning disabilities are more likely to experience sexual abuse than the general population. Research has also consistently shown that this group is less likely to be offered 
support that they find meaningful (McCarthy 1999; Howlett \& Dandby, 2007; Olsen \& Harris, 2012).

Literature suggests that women with learning disabilities struggle to access rape and sexual assault services for several reasons. These reasons include vulnerability due to lack of sex education and social pressure; lack of accessible information about where support services are and how to access them, and people who work in services not feeling adequately trained to work with people with learning disabilities following sexual assault (Olsen \& Harris 2012, Olsen \& Carter 2016). These studies indicated that there is some confusion between mainstream and learning disability services. They suggest that while professionals in each service understand their own remit, many are unclear about the role and remit of others. Research examining the experiences of women with learning disabilities who had reported rape found that service providers often referred people with learning disabilities to other services because they felt lacking in skills to support them, (Olsen \& Harris 2012). Women in this study likened their treatment to a 'revolving door' whereby they were continually referred from one service to another and back again. Ultimately they were unable to access mainstream services or receive support that they found useful. This resulted in these women sometimes feeling misunderstood and disbelieved (Bailey and Barr 2000).

This paper explores the ability of St Mary's Sexual Assault Referral Centre (SARC) to provide meaningful support to people with learning disabilities. St Mary's SARC provides a comprehensive and co-ordinated forensic, counselling and aftercare service to men, women and children living in Greater Manchester who have experienced rape or sexual assault, whether this is an acute case or historic. The St Mary's SARC comprises a team of experts with a wealth of knowledge and experience in advising, supporting and treating anyone who reports being raped or sexually assaulted. In 2012/3 1221 patients were seen; circa $10 \%$ were male and $90 \%$ were female. Patient evaluation consistently shows that the St Mary's SARC has an excellent record of supporting people who have been sexually assaulted and the service is committed to continually improve its responses for all (SARC Annual Report, 2013). 
This paper presents findings from a service evaluation undertaken by the SARC staff in 2013, supported by an academic partner. Findings are presented here as a baseline from which change can be measured; this will be reported in a subsequent paper where the intervention delivered in the interim is also detailed.

\section{Method}

The service evaluation was undertaken in May 2014 and had two components. The first component used a survey to elicit self-perception of the knowledge and skills of the SARC clinical and support staff in respect of people with learning disabilities who attended the SARC following an allegation of rape or sexual assault. The objective of administering the survey was to explore what the staff believed they knew about people with learning disabilities and to identify areas for further training. The second component consisted of an audit of patient notes collected at the SARC to compare patients with a learning disability to those without. The objective of the notes audit was to document and evaluate where similarities and differences may occur in the nature of the case and the response to it.

The components will be presented in turn here and in the results sections. The parts will be used to illuminate one another in the discussion. The purpose of the study is to explore ways in which staff knowledge, skills and confidence affect the way they worked with people with learning disabilities.

Approval was gained from the Research and Innovation department of the NHS foundation trust (R03685 Service Evaluation).

\section{Staff survey}

The staff survey was developed in consultation with a group of practitioners from the St Mary's SARC, a focus group of people with learning disabilities and group of nurses and social workers from partner agencies who specialised in working with people with learning disabilities. The survey was then trialled by two SARC staff members to check the likely length of time that it would take to complete and to check the questions for ease of understanding. Following positive feedback, it was posted on Survey Monkey where it was available for two weeks. This method was chosen because it was quick and easy to 
administer and could provide a timely snapshot of current data. A link was emailed to all St Mary's SARC staff in order to gather as much information as possible about how the centre works as a whole for people with learning disabilities.

The staff survey sought to explore the following:

- The levels of staff understanding of learning disabilities

- How equipped staff felt when working with people with learning disabilities

- What staff thought that the SARC could do to improve its service to people with learning disabilities.

\section{Patient notes audit}

The patient notes audit consisted of a paper and computer file audit of two cohorts of adult patients (aged >18years old) who had alleged a sexual assault and received a Forensic Medical Examination (FME). The inclusion criteria of 'over 18s' was chosen as there are separate processes involved for children to consent. Only St Mary's SARC patients who had attended for an FME were included in this study because decision making around capacity to consent/best interest decision was a key component of the audit.

Cohort 1 was comprised of patients with a self-reported learning disability meeting the inclusion criteria during the study period of December 2011 and December 2013. There were 74 people in this cohort. Cohort 2 , the control group, consisted of a random selection of 74 adults, who did not disclose having a learning disability and were seen over the stated time frame. Both cohorts were identified by the same process of manually looking at the 'disability' section on the patient paper administration forms and, where required, computerised records from the SARC's database.

Audit data was gathered to identify the following:

- Gender of patient

- Whether the alleged perpetrator was known to the patient

- Number of Independent Sexual Violence Advocate (ISVA) calls made to each patient. ISVA's are support workers to help people who have been sexually assaulted.

- Number of patients who had accessed counselling at the SARC 


\section{Findings}

\section{Staff survey}

42 members of staff (over $75 \%$ response rate) completed the survey. Job roles of participants were: Crisis Worker (10); Forensic Doctor (20); Counsellor (4); ISVA (3); Child Advocate (1); Administrator (2); Management (1) and Young Persons Advocate (2). One individual entered two roles to reflect their job. While the majority of staff had worked at the centre between 1-5 years, almost a quarter had more than 10 years' experience of SARC work.

To the survey question 'The Client Details Form asks you to record whether or not the client has a disability. Which of the following would you include under the heading of learning disability? Please tick all that you would include.' The recorded responses are presented in Table 1. It should be noted only 40 of the 42 staff members answered this question, two of the staff members stated that they do not fill out the client details form.

\section{Table 1 about here}

We explored how recognition of a learning disability might impact on a practitioner's ability to do their job. Fifteen of 42 responders thought that they had quite a lot of knowledge, another 18 felt that they had 'just enough knowledge' of learning disabilities to do their job. Nine responders reported 'little specific knowledge', or 'not enough' to do their job as well as they would like. These results are presented in Table 2.

\section{Table 2 here}

This self-perceived lack of learning disability specific knowledge however did not lead to an overall lack of confidence when working with people who had learning disabilities, with 30 of 42 responders feeling confident in their ability to support people well. Nine responders felt unable to answer the question, while three responders reported not feeling confident when working with a person who had a learning disability. These results are presented in Table 3. One person qualified her 'not confident' response, stating, "hesitate between confident and not sure - feel I would apply my professional training to working with people with learning disabilities and could adapt but not sure that this would be the best possible practice". This statement suggests that a detailed understanding of an underlying condition 
such as learning disability may not be as important as an ability to work appropriately with a person with an acute presenting condition requiring prompt action, i.e. a person who has been sexually assaulted. The self-questioning about best practice indicates reflection in practice and as such suggests that the process of completing the questionnaire may have prompted the practitioner to think about her learning disability knowledge.

Table 3 here

The survey also questioned staff member's understanding of any existing support services that might be in place for patients with learning disabilities that attended St Marys SARC. The majority of staff surveyed indicated that they were not sure or not confident that the patient would have on-going support. Responses to this question are presented in Table 4. SARC staff members' perceptions of existing support services that might be in place for patients with learning disabilities that attended the centre were in contrast to commonly held professional beliefs, as has been reported in the wider literature. In a study undertaken by Olsen and Carter (2016) it was reported that professionals believed people with learning disabilities would usually have access to specialist learning disability services that could support them in times of crisis. In contrast to this, the St Mary's staff survey indicated that only seven respondents thought people with learning disabilities had ongoing support with the majority of 35 being unsure or not confident that the patient would have external professional support because of their learning disability already in place.

Table 4 here

To the question, "Do you think SARC's should provide training on Learning Disability?" an overwhelming $100 \%$ of respondents answered "Yes". A series of questions followed which illuminated areas respondents felt that they had the most need for training. Staff responses to these are outlined in Table 5, it should be noted that the 42 participants were invited to select as many options as they wished in response to this question.

Table 5 here 
The staff survey also invited suggestions for areas of personal and organisational improvements. Respondents were allowed free text boxes to answer the question: "What resources or people should be available to support you in your work with people with LD?" There was a range of responses to the question which included: "Someone at the centre with specialist knowledge so they could advise"; "Leaflets, better links with learning disability teams in areas we cover" and "More outreach from ISVA/child advocate point of view as access may be limited to the centre".

\section{Patient notes audit}

The patients note audit included 74 patients in the learning disability cohort (63 women and 11 men) and 74 patients in the cohort without learning disabilities (69 women and 5 men). Patient notes were examined to identify alleged perpetrator's relationship to the patient and whether this varied by cohort. The level of involvement from follow-up services was also assessed to determine whether there was any variation in the two cohorts.

\section{Alleged Perpetrators}

The patient data audit revealed many similarities between the cohorts in terms of alleged perpetrators, see Figure 1. For example strangers and acquaintances were cited most frequently as alleged perpetrators in both cases although strangers were more commonly cited by the control group (Control n24, Learning Disability n17) and acquaintances slightly more commonly cited by the Learning disability group (Learning Disability n24, Control n20). Family members were cited infrequently by both cohorts (Learning Disabilities $n 5$, Control n3).

Figure 1 here

\section{Forensic Medical Examination}

In the two year study period approximately 1500 adults were referred to the centre, 74 of whom self-reported as having a learning disability, all of whom underwent a forensic medical examination FME (as was outlined in the inclusion criteria). Prior to any FME the Forensic Physician assessed the mental capacity of the patient as per the Mental Capacity Act (2005). This is a complex and skilled process and involves determining a number of 
issues including whether or not there is an impairment of or disturbance in the functioning of the mind or brain, if yes, is it permanent, temporary or fluctuating? The assessment needs to bear in mind what the person is being asked to consent to, whether they understand the need for a forensic medical examination and what options are open to them, that they can retain the relevant information long enough to make a decision, they are able to use or weigh up the information as part of the decision making process and finally that they are able to communicate their decision.

Of the learning disability cohort, 69 patients were deemed to have capacity to consent to the FME. The remaining five patients of the cohort were recorded as having a severe learning disability, all of whom underwent a FME being examined after a decision that it would be in their "best interest" as per the Mental Capacity Act (2005). Only two of the five patients with severe learning disabilities had clear documentation of a best interest assessment having taken place. It is important to note that a lack of evidence of assessment does not equate to a lack of assessment; but rather that the evidence is not recorded in case notes. Everyone in the control group also underwent a FME (as was outlined in the inclusion criteria).

\section{ISVA follow-up services}

The experiences of the cohorts began to diverge when we examined what happened to the patient following the FME. Patients with learning disabilities accessed the ISVA service markedly less frequently than patients without learning disabilities. ISVAs are support workers who will contact the person who has been sexually assaulted within five days of their FME. The ISVA will listen to them and give them the information they need and that is relevant to their circumstances. There was an average of four follow up calls being made to patients with learning disabilities, while seven calls were made to patients from the control group, see Figure 2.

Figure 2 here 
Counselling is available to all patients who have attended St Marys SARC following a sexual assault. Only one person from the learning disability cohort accessed the counselling offered by the centre as compared to 12 patients from the control group. Some patients reported seeking counselling outside the service (two patients from the learning disability group and one from the control group). These figures suggest that people with learning disabilities who have experienced sexual assault or rape were $50 \%$ less likely to access counselling than people without learning disabilities.

\section{Discussion}

Is an accurate assessment of learning disability necessary in order to ensure a fully supportive service?

The patient notes audit relied primarily on self-reporting of learning disability by the people accessing the service, this was supplemented by staff's professional judgement regarding the likelihood of a person having a learning disability if the patient had not declared it in the initial stages of the interaction when asked directly. The staff survey revealed that the majority of staff considered dyslexia, dyspraxia, ADHD and autism to be forms of learning disability - these conditions, together with Tourette's, have been brought together by patients groups under the umbrella term of neurodiversity. Neurodiversity, is understood to include 'Difficulties with organisation, memory, concentration, time, direction, perception, sequencing, poor listening skills leading to low self-esteem, anxiety and depression.' (DANDA: www.achieveability.org.uk). These characteristics are also seen in many people with learning disabilities. However the conditions themselves are not considered to be learning disabilities according to the UK definition as stated in Valuing People (2001).

It is easy to see why professionals may struggle to diagnose their patients accurately when people with differing disabilities, such as learning disability and other neurodiverse conditions may share similar characteristics. A clinician assessing any patient who has experienced a sexual assault is confronted with a person who may be in great distress. Common reactions to sexual assault include shock, disbelief, fear of not being believed, loss of self-confidence, confusion in time, shame, anxiety, depression and anger; all of which impact on an individual's ability to function normally. Recognising and understanding to 
what extent current functioning (ICF 2001) is due to the assault and what might be due to a pre-existing condition can be extremely difficult in such circumstances. This is not simply a dilemma for the St Mary's SARC team, previous studies of differing professions have also highlighted the challenge of accurate recognition (Arvidsson, Granlund and Thyberg 2105, Douglas and Cuskelly 2011).

When staff in this study were asked to tell us how they diagnosed learning disabilities in a patient, most of them selected 'professional knowledge' in the multiple choice question. When asked a similar question, other professionals have cited appearance, communication and gait as indicators of learning disability, while recognising that simple observation could lead to misidentification (Douglas \& Cuskelly, 2012). Douglas and Cuskelly concluded that the use of a screening tool might help to militate against future errors. The call for a screening tool to facilitate the diversion of people with learning disabilities from the criminal justice system has also been made in the UK (Hayes 2002, Bradley 2009). The latter leading to the development of the learning disability screening questionnaire (LDSQ).

The LDSQ is a commercially available tool containing seven questions. Providers of the LDSQ suggest that it is effective for use by people without any previous knowledge or training in learning disabilities. Studies into the effectiveness of the tool suggest that it can be used in other settings and that it can accurately discriminate between people with and those without a learning disability, although it cannot classify severity of disability (McKenzie K., Michie A., Murray, A. \& Hales, C. (2012); Murray \& McKenzie 2014). It is of interest to note that the creators of the LDSQ were responsible for both of these validity test studies and independent assessments are not available at the time of writing this paper. In the absence of other validated tools that can be used efficiently in a clinical setting St Mary's SARC is trialling the LDSQ to determine whether it facilitates provision of a fully supportive service.

By screening for a learning disability at the FME stage, the ISVA and counselling follow-up services can be alerted to the needs of the patient thereby enabling a more empowering patient journey. 
Service response to sexual assault: St Mary's SARC

Is an accurate assessment of the capacity to make decisions necessary in order to ensure a fully supportive service?

Many respondents to the staff survey believed that they would benefit from training in the recognition of learning disability and the majority also identified training in assessing mental capacity and best interest decision making as being important. Thus indicating that while practitioners are making best interest decisions with due diligence at present they would welcome more guidance.

It is likely that currently, support and recovery are prioritised over diagnosis of disability. Supporting a person who has been sexually assaulted requires decision making about what happens to the individual following disclosure. Some of these decisions will be complex and require an immediate response; such as whether or not to undergo the FME. Although all 74 of the people with learning disabilities in our study underwent the FME (since this was the inclusion criteria), five of these were judged as not competent to make the decision to be examined. All five of these cases had the FME after a decision that it was in their "Best Interest" as per the Mental Capacity Act (MCA) 2005. The MCA allows a clinician to assess an individual's mental capacity and make a judgement about whether or not the individual has capacity to make a specific decision for themselves. .

St Mary's SARC staff members also identified some simple adjustments that they believed might make things more comfortable, or less distressing for people with learning disabilities accessing the service. Suggestions ranged from having clearer signposting, easy read literature and pictures available in waiting areas, to having someone at the centre with specialist knowledge who could liaise between staff and people with learning disabilities. Existing accessible resources such as the 'Don't put up with it' produced by the Tizard centre (https://vimeo.com/116967832[1] ) might be useful for SARC waiting rooms. The St Mary's SARC staff also identified that further outreach work could be beneficial in shared awareness raising. They could assist in the better recognition of learning disabilities and appropriate responses amongst SARC staff as well as raise awareness of the increased vulnerability to sexual assault for people with learning disabilities as well as services that can support them. 


\section{Limitations of the study}

The accuracy of the data is governed by the understanding and precision of the person who is inputting it and it appears that staff had no clear collective guidance as to what constitutes a learning disability prior to this study. Reliance was therefore largely on selfreporting by the person with a learning disability, so it is anticipated that the figures reported will include false positives and false negatives. This may be further complicated by conflation of the terms learning disability and learning difficulty. This is a common problem in this area. As result of the findings from the staff survey and patient notes audit the St Mary's SARC team have undertaken a body of work to identify and overcome challenges; these will be detailed in a subsequent paper.

This paper positions a research study in the larger context so as to develop a more effective professional response to people with learning disabilities who have experienced sexual violence. We remain mindful however that since our research has been undertaken in one large urban conurbation it is limited to one SARC so cannot be generalizable on its own. It may therefore be worthwhile extending the work to other geographical regions to further explore trustworthiness of findings. The survey could also be refined as a result of the lessons learnt from this work. For example, interpretations were made difficult because in some cases where participants chose not to answer a question and in others where they chose multiple answers.

\section{Conclusion and recommendations}

Our study highlights a lack of differentiation between learning disabilities and other types of neurodiversity. This is a common theme across the research domain and supports the call for a focus on support rather than labelling. The Mental Capacity Act (2005) provides guidance that enables practitioners to make judgements about a patient's capacity to make decisions, and provides a framework for decision making where people lack capacity. However, practitioners have identified a need for further training in identifying and communicating with people with learning disabilities so that they can be as certain as possible that they are acting in accordance with their wishes and providing personalised support. 
Service response to sexual assault: St Mary's SARC

While we are mindful that the study sought to improve services for people with learning disabilities we believe that the lessons learned and changes made could have positive benefits for people with other neurodiverse conditions. 


\section{References}

Arvidsson, P., Granlund, M. and Thyberg, M. (2015) How are the activity and participation aspects of the ICF used? Examples from studies of people with intellectual disability. Neuro Rehabilitation, 36: 45-49

Bailey, A. \& Barr, O (2000) Police policies on the investigation of sexual crimes committed against adults who have a learning disability. Journal of learning disabilities. 4: 129-139

Beail, N. and Warden, S. (1995) Sexual abuse of adults with learning disabilities. Journal of Intellectual Disability Research, 39: 382-387. doi:10.1111/j.1365-2788.1995.tb00542.x

Bradley (2009) Lord Bradley's review of people with mental health problems or learning disabilities in the criminal justice system.http://webarchive.nationalarchives.gov.uk/20130107105354/http://www.dh.gov.uk /prod_consum_dh/groups/dh_digitalassets/documents/digitalasset/dh_098698.pdf Brown, H. and Craft, A. (1989) Thinking the unthinkable: Papers on sexual abuse and people with learning difficulties. London: FPA Education Unit.

Brown, H., Stein, J. and Turk, V. (1995) The sexual abuse of adults with learning disabilities: report of a second two-year incidence survey. Mental Handicap Research, 8: 3-24. doi:10.1111/j.14683148.1995.tb00139.x

Brown, H. and Turk, V. (1994) Sexual abuse in adulthood: Ongoing risks for people with learning disabilities. Child Abuse Review., 3: 26-35. doi:10.1002/car.2380030106

Brownridge, D. A. (2006). Partner violence against women with disabilities. Violence Against Women, 12: 805-822.

Buchanan AH \& Wilkins R. (1991) Sexual abuse of the mentally handicapped: difficulties in establishing prevalence. Psychiatric bulletin. 15: 601-605 
DANDA. http://www.achieveability.org.uk/files/1275491669/neuro-diversity-diagram.pdf (last accessed 4 July 2016)

DH (2001), 'Valuing People': A strategy for learning disability in the 21st century. https://www.gov.uk/government/uploads/system/uploads/attachment_data/file/250877/5 086.pdf (last accessed 13 October 2016)

Douglas, L. and Cuskelly, M. (2012) 'A focus group of Police officers' recognition of individuals with intellectual disability.Psychatry, Psychology and Law, 19: 35-44 DOI: 10.1080/13218719.2010.543403

Etchells, E., Daizins, P., Siberfeld, M., Singer, P.A., McKenny, J., Naglie, G., Katz, M., Guyatt, G.H., Molloy, W. and Strang, D. (1999) 'Assessment of patient capacity to consent to treatment'. Journal of general internal medicine, 14:27-34.

Grossman, S.F. \& Lundy, M. (2008) Double jeopardy: a comparison of persons with and without disabilities who were victims of sexual abuse and/or sexual assault. Journal of Social Work in Disability and Rehabilitation, 7:19-46

Hard S. \& Plumb W. (1987) Sexual abuse of persons with developmental disabilities. In: V.Turk and H. Brown, editors. The sexual abuse of adults with learning disabilities: Results of a two-year incidence survey. Mental Handicap Research, 6: 193-216

Hayes, S. (2002) Early intervention or early incarceration? Using a screening test for intellectual disability in the criminal justice system. Journal for applied research in Intellectual Disability. 15: 120-128

Hogg, J., Campbell, M., Cullen, C. and Hudson, W. (2001) Evaluation of the Effect of an Open Learning Course on Staff Knowledge and Attitudes Towards the Sexual Abuse of Adults with Learning Disabilities. Journal of Applied Research in Intellectual Disabilities, 14: 12-29. doi:10.1046/j.14683148.2001.00049.x 
Howlett, S. and Dandby, J. (2007) "Learning Disability and Sexual Abuse: Use of a Woman-Only Counselling Service by Women with a Learning Disability: A Pilot Study", Tizard Learning Disability Review, 12: 4-15

International Classification of functioning (ICF 2001) http://www.who.int/classifications/icf/en/ ( last accessed 13 October 2016)

MacKenzie, R. and Watts, J. (2011) Can clinicians and carers make valid decisions about others' decision-making capacities unless tests of decision-making competence and capacity include emotionality and neurodiversity? Tizard Learning Disability Review, 16:43-51

McCarthy, M. (1999), Sexuality and women with learning disabilities. London: Jessica Kingsley

McKenzie, K., Michie, A., Murray, A. and Hales, C. (2012) Screening for offenders with an intellectual disability: The validity of the Learning Disability Screening Questionnaire. Research in Developmental Disabilities, 33 91-795

Mental Capacity Act (2005).

https://www.gov.uk/government/uploads/system/uploads/attachment_data/file/497253/Mentalcapacity-act-code-of-practice.pdf (last accessed 13 October2016).

Murray, A.L., and McKenzie, K. (2014) The accuracy of the Learning Disability Screening Questionnaire (LDSQ) in classifying severity of impairment: A brief report. Journal of Intellectual and Developmental Disability, 39: 370-374. DOI:10.3109/13668250.2014.936836

Olsen, A., \& Harris, K. (2012) Social care online: Saying no to sexual violence. www.sciesocialcareonline.org.uk/saying-no-to-sexual-violence. (last accessed 4July 2016)

Olsen, A. \& Carter, C. (2016) Responding to the needs of people with learning disabilities who have been raped: co-production in action. Tizard Learning Disability Review, 21:30-38 
Powers, L.E., Hughes, R.B. and Lund E.M. with contributions from Wambac, M. (2011) Interpersonal violence and women with disabilities: a research update. National resource center on domestic violence.

Schalock, R.L. (2011) The evolving understanding of the construct of intellectual disability. Journal of Intellectual \& Developmental Disability, 36:223-33.

doi:10.3109/13668250.2011.624087

St Marys SARC. (2013). Sexual Assault Referral Centre Annual Report: April 2012-April 2013. [online]. Available at: https://www.stmaryscentre.org/wp-content/uploads/2013/11/1219544-SARC-Annual-Report-2013.pdf [Accessed 25 Oct. 2016].

Williams, V., Swift, P. \& Mason, V. (2015) The blurred edges of intellectual disability. Disability and Society, 3: 704-716 
$\underline{\text { Tables and Figures }}$

\begin{tabular}{l|c}
\hline Answer Choices & Responses \\
\hline Dyslexia & 32 \\
\hline Dyspraxia & 27 \\
\hline Autism & 31 \\
\hline Asperger's syndrome & 24 \\
\hline Down's syndrome & 33 \\
\hline Unable to read and write (no reason given) & 26 \\
\hline ADHD & 18 \\
\hline
\end{tabular}

Table 1 "Which of the following would you include under the term "learning disability"?

\begin{tabular}{|l|l|l|l|l|r|}
\hline $\begin{array}{l}\text { I am an } \\
\text { expert }\end{array}$ & $\begin{array}{l}\text { Quite } \\
\text { a lot }\end{array}$ & $\begin{array}{l}\text { Just } \\
\text { enough to } \\
\text { do my job }\end{array}$ & $\begin{array}{l}\text { Not enough to } \\
\text { do my job as } \\
\text { well as possible }\end{array}$ & $\begin{array}{l}\text { Very little } \\
\text { specific } \\
\text { knowledge }\end{array}$ & Total \\
\hline 0 & 15 & 18 & 6 & & 32 \\
\hline
\end{tabular}

Table 2 "How much do you know about learning disabilities?"

\begin{tabular}{|l|l|l|l|l|l|}
\hline $\begin{array}{l}\text { Very } \\
\text { confident }\end{array}$ & $\begin{array}{l}\text { Quite } \\
\text { confident }\end{array}$ & $\begin{array}{l}\text { Not } \\
\text { sure }\end{array}$ & $\begin{array}{l}\text { Not } \\
\text { confident }\end{array}$ & $\begin{array}{l}\text { Really not } \\
\text { confident }\end{array}$ & $\begin{array}{l}\text { Number of } \\
\text { respondents }\end{array}$ \\
\hline 1 & 29 & 9 & 3 & 0 & \\
\hline
\end{tabular}

Table 3 "How confident do you feel when working with a patient who has a learning disability?"

\begin{tabular}{|l|l|l|l|l|}
\hline $\begin{array}{l}\text { Very } \\
\text { confident }\end{array}$ & $\begin{array}{l}\text { Quite } \\
\text { confident }\end{array}$ & $\begin{array}{l}\text { Not } \\
\text { sure }\end{array}$ & $\begin{array}{l}\text { Not } \\
\text { confident }\end{array}$ & $\begin{array}{l}\text { Number of } \\
\text { respondents }\end{array}$ \\
\hline 0 & 7 & 22 & 13 & 42 \\
\hline
\end{tabular}

Table 4 "How confident are you that all patients with learning disabilities will have some external professional support (because of their Learning Disability) already in place?" 
Service response to sexual assault: St Mary's SARC

\begin{tabular}{|l|l|l|l|l|}
\hline $\begin{array}{l}\text { Basic } \\
\text { introduction } \\
\text { to } \\
\text { learning } \\
\text { disabilities }\end{array}$ & $\begin{array}{l}\text { How to detect if } \\
\text { a person has a } \\
\text { learning } \\
\text { disability }\end{array}$ & $\begin{array}{l}\text { How to } \\
\text { communicate } \\
\text { with people } \\
\text { with } \\
\text { learning } \\
\text { disabilities }\end{array}$ & $\begin{array}{l}\text { Mental } \\
\text { capacity } \\
\text { and consent } \\
\text { assessment }\end{array}$ & $\begin{array}{l}\text { Best interest } \\
\text { decision } \\
\text { making }\end{array}$ \\
\hline 28 & 26 & 35 & & \\
\hline
\end{tabular}

Table 5 "What would you want this training to include?" 